\title{
Urban Performances: Hazards, Risks and Technological Developments
}

\author{
Bouzid Boudiaf* \\ Department of Architectural Engineering , Ajman University of Science and Technology, United Arab Emirates
}

*Corresponding author: Bouzid Boudiaf, Department of Architectural Engineering, Ajman University of Science and Technology, United Arab Emirates

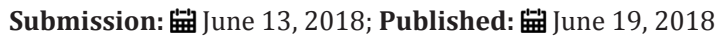

\section{Introduction}

Civilization is the advanced social development that is believed to owe its origin to human interaction in cities. But cities do not always have a civilizing effect. In history, the size of a population has corresponded to the availability of resources, particularly food and water. Ever since the Age of Agriculture, the stability of food supplies and the relative security of group settlements have decreased mortality rate and increased fertility. The consequent increased demand leads to exploitation of resources, which invariably exceeds the accessible supply. As a result, a cyclical population decline occurs, through starvation, disease, social and economic declination, migration and war (Facing The Future: People and the Planet 1997). Historical examples abound: recurring famines, the Black Death, colonization, the two World Wars. As cities have historically been a place of gathering, of diversity and culture, trends in city planning are redefining the structure of cities into segregated zones separating the haves and the have-nots. Classified by political theorist Michael Walzer as "single-minded" spaces, most metropolises today comprise distinct business districts, industrial zones, shopping arcades, uptown residences, and lower class or racial ghettos. In contrast to "open-minded" spaces that interweave multiple functions for the masses, single-minded spaces, along with automobile dependency, promote social isolationism, in which city residents tend to minimize interaction with and within the city and the diversity thereof. In addition, the decentralization of megacities to a greater urban sprawl spring a number of design issues, including the harmonization of new business districts, mix-income residences, and land allocation for green areas. At present, urban development continues to follow the piecemeal approach, where districts are designed as an isolated project. Furthermore, infrastructure such as roads and public transportation must be considered with the environment and population density. In most of the countries (since the industrial revolution for some European countries) and in the beginning of the 1960's in South America and Africa, it had been noticed a huge and unexpected migration from the rural to the urban areas. The attraction and migration to the urban areas can be explained by the search for a diversified environment (different ethnics, multitude of activities) offering many opportunities (in terms of jobs, leisure, health, communication, etc.) with the hope to change the social status, offer a better education to their progenitor. Certainly, this attraction has some positive aspects (amenities offered, well-being, increase of knowledge, etc.) but it has also some negative aspects from the environmental and psychological (anonymity, noise, aggression, vandalism, pollution, robbery, crimes, etc.). These negatives aspects led to a social and physical segregation of the city, usually the areas with a high-rise buildings or occupied by a low-income lack of gardens or playground for children and most of the urban furniture are damaged physically or having some graffiti on them. It seems that there is a very strong correlation between crime and density. In fact this kind of behavior is not specific to our contemporary life. Historically, and from the chronological point of the view, it was Leonardo De Vinci who tried to construct a safety space. Then the utopian who developed some spatial organizations highlighting the hygienic issues, and later Henard, Howard and Perry with their interests on the traffic problems, and public safety led to the development of a new of thinking about the production of our build environment and called Environmental Design.

Since 1980's, cities are facing different types of risks: those related to anomie (such as physical decay, incivilities, crime...), but also accidents provoked by human activities (pollution due to chemicals, airplane accidents, gas explosion), natural hazards (earthquake), or terrorism menaces. The world seems increasingly concerned with the problems of a deteriorating environment: global climate change, vanishing plant and animal species, reliance on fossil fuels, and the inappropriate development of natural and productive landscapes, there is a marked tendency to bypass the urban environment. When seen in the context of the impact of humans on world ecosystems, it is clear that the links between cities, nature, and sustainability have profound impacts on the global environment. Urban open spaces are focal points in urban design and an important part of the fabric of any community. They serve as the public realm and environment for the surrounding buildings. They also provide a range of tangible benefits, such as mitigating air and water pollution, combating suburban sprawl, providing opportu- 
nities for recreation, reducing crime and fostering cohesive neighborhoods, attracting businesses, and stabilizing property values. As part of a broader urban agenda, investing in open space can serve as an anchor for revitalizing neighborhoods and building healthy communities. So well-designed urban open spaces are the heart of the matter. The degree the neighborhood is sustainable depends on its urban design. A good urban design is the key for any balanced and sustainable development. In 1990's, some countries succeeded to decrease to some extend the migration to the big cities, but another phenomena appeared. The menaces of terrorism led to the migration to the urban areas and principally to the big cities. (c) (i) Creative Commons Attribution 4.0 International License

For possible submissions Click Here

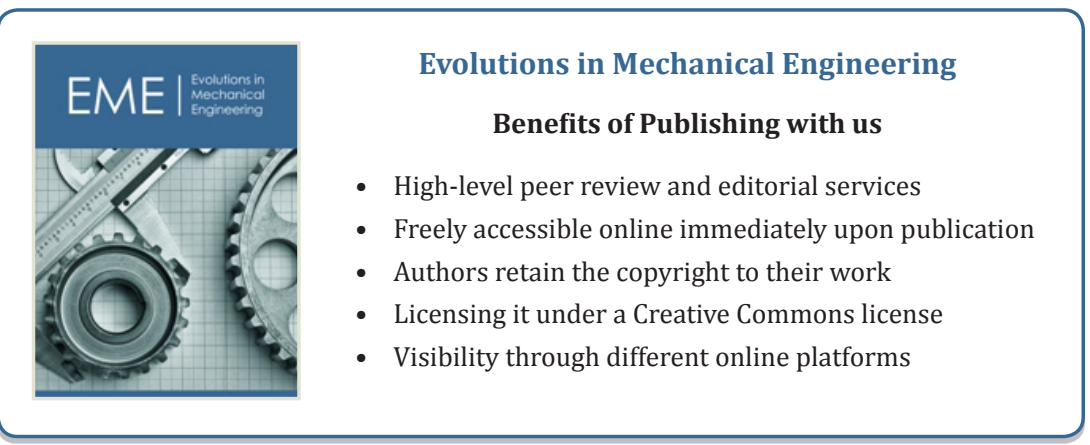

